\title{
The Suitability of GC-MS Simulated Distillation as Means to Determine the Boiling Range of Biodiesel
}

\author{
CJ Schabort and AA van der Merwe
}

\begin{abstract}
The suitability of GC-MS simulated distillation as means to determine the boiling range of biodiesel is determined in this study. The study is divided into two sections. Various vegetable oils and animal fats where an acid- and/or alkali-catalyst can be used and diluted with an alcohol to produce biodiesel. The produced biodiesel must meet the SANS 1935:2011 standards where it can be used for diesel engine automobiles [1]. The first section is known as the experimental procedure for the production of biodiesel from various feedstock's and the second section includes the distillation experiment of the biodiesel. The distillation procedure followed the same procedure as specified by the ASTM D86 test method. The test method indicates that the distillation unit must operate at atmospheric pressure but the distillation experiments were conducted at ambient pressure of $86.02 \mathrm{kPa}$ for Potchefstroom. The actual distillation curve and the simulated distillation curve for each biodiesel were compared in order to see if the simulated distillation results predict the same boiling points as the actual distillation. This study has shown that the simulated results obtained from the GC-MS can be used to determine the boiling ranges for biodiesel but it can be better accomplished by using vacuum distillation.
\end{abstract}

Index Terms- Ambient pressure, biodiesel feedstock, conventional one-step process, conventional two-step process, distillation, simulated distillation

\section{INTRODUCTION}

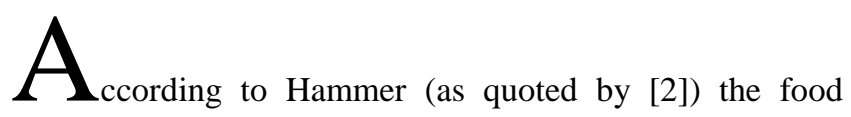

versus fuel concept never existed before the mid-nineteenth century. Due to the improved technology and waste treatment, waste cooking oil can be reused to produce biodiesel. The biodiesel production has increased in the last decade to counter increased crude oil prices and resource depletion in the past decade. The demand for biodiesel has increased from 2001 to 2015. The increase in the demand for the production and consumption of biodiesel in the United States are shown in Fig 1 [3].

AA van der Merwe is School of Chemical and Minerals Engineering, North West University Potchefstroom, South Africa (corresponding author's e-mail: 24155039aa@gmail.com ).

CJ Schabort is with School of Chemical and Minerals Engineering, North West University Potchefstroom, South Africa

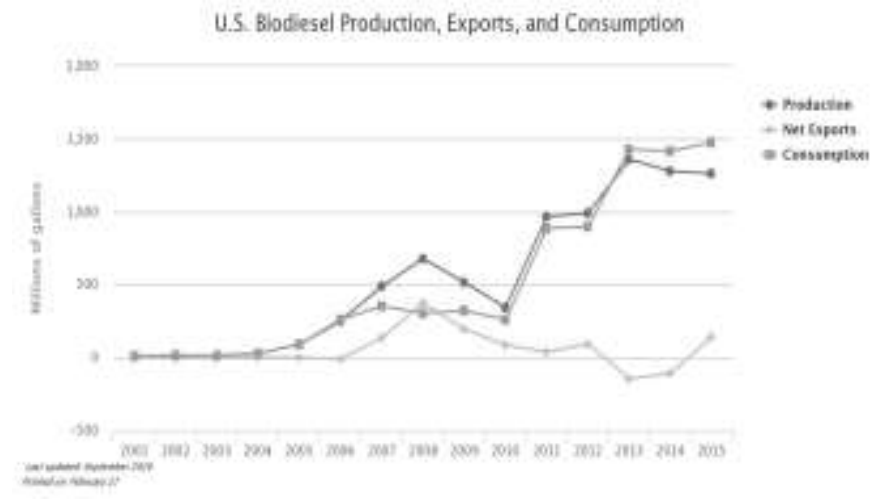

Fig 1: Graph of the U.S biodiesel production, exports and consumption from 2001-2015 [3].

Fig 1 shows that biodiesel production and consumption have increased considerably since 2010. This can be explained by an international drive towards cleaner fuels and a lower dependence on fossil fuel as energy source.

Fig 1 shows that the production of biodiesel has increased since 2008 and is still increasing all the way. The increase in the production of biodiesel means that there are more biodiesel producers entering the market. More biodiesel manufacturers leads to an increase in the biodiesel production.

Biodiesel is biofuel that is produced from waste cooking oil, animal fats, and alcohol. Biodiesel can only be used in diesel engines (compression-ignition engines) [4]. Biodiesel was first discovered by Rudolf Diesel where he made diesel from peanut oil at the 1900 World Fair in Paris. After Diesel's bold effort of making diesel from peanut oil, a French company performed a run on a diesel engine simply on peanut oil and it became a success [5]. From there on, countries all over the world started to make biodiesel from the concept that Diesel made biodiesel.

Biodiesel standards ensure that all impurities are removed from the biodiesel so that it cannot damage the diesel engine or the automobiles filters, as it can be one of the main factors form damage done to engines. A distillation curve determines the boiling range of biodiesel. The quality of the biodiesel can be determined form various parameters in which boiling points can relate to the quality of biodiesel. A couple of methods determine this parameter which can be given by the GC-FID meter. The GC-FID will not be used but will be replaced with a GC-MS. The GC-MS is a well-trusted type of testing equipment but there are only a few studies that compared their result with actual distillation experiment for this equipment. Another method is by using an actual 
atmospheric distillation column, to plot a distillation curve. The simulated distillation curve can be compared to the actual distillation curve in order to see the tendency of each method.

\section{ENERGY}

Around $80 \%$ of total energy consumption worldwide is sustained by fossil fuels [7]. Therefore, the depletion of natural resources will be problematic. As seen in Fig 2, liquid fuel consumption has increased over the last couple of years and is expected to further increase up to 2040. According to [3], a $48 \%$ increase in world energy consumption by 2040 is projected, where fossil fuels will account for around $75 \%$ of the increase.

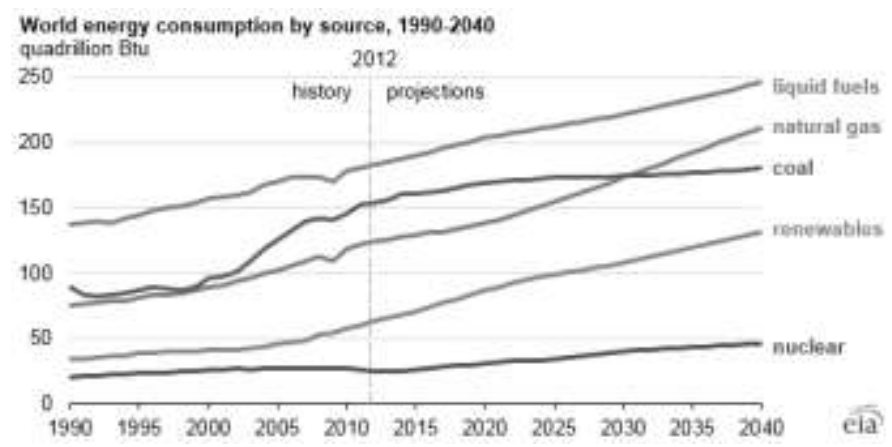

Fig 2: World energy consumption by source [8]

\section{A. Natural Resources-Fossil fuels}

Fossil fuel consumption has increased due to the increase in transportation in the process of industrialization. Due to the high demand for fossil fuels and the negative impact that it has on the environment, a sustainable strategy must be implemented for alternative sources of fuels. As already shown in Fig 2, the demand for diesel fuels will increase in the years to come and this can lead to environmental impacts which include $\mathrm{CO} 2$ emissions increasing and natural resources to become depleted.

\section{1)Types of fossil fuels}

Fossil fuels like coal, oil and natural gas [9], are limited, necessitating a need for sustainable alternatives. Oil is mostly used in producing petroleum products. The increase in population has led to an increase in petroleum product consumption, explaining the increase in oil demand. According to [10], it was estimated that oil reserves will be depleted by 2030 if the consumption and production of petroleum increases. The consumption of oil reserves at the end of 2014 was around 1656 billion barrels and this number has increased around 3.1 times since 1971 [10]. The highest demand of energy consumption is for non-renewable fossil fuels. This high demand will be problematic in the future due to the depletion of crude oil and fossil fuels. Coal is the second most used energy source around the world [11]. Fig 3 shows a projection of the depletion by 2080 if coal consumption increases.

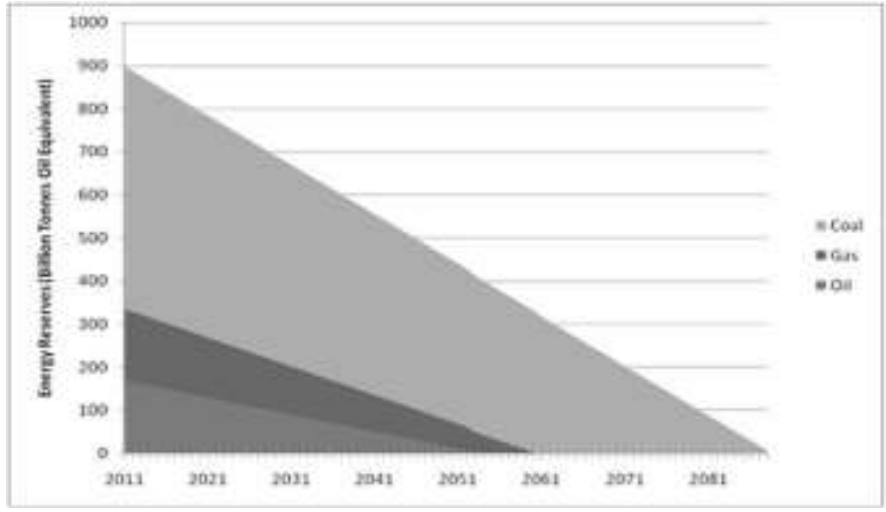

Fig 3: Statistics regarding the depletion of various natural resources [12]

Fig 3 shows a projection that natural gas will be depleted by 2050 . The US has consumed around $33 \%$ of natural gasses in 2015 [10] due to industrial applications and this can lead to an increasing factor of the depletion of natural gasses. A sustainable strategy must be developed in order to use less fossil fuel.

Fossil fuels, as a primary source of energy, directly impact the world economy [13]. The constant use of fossil fuels contributes to global warming due to the increase of carbon emissions into the atmosphere. Carbon emissions into the environment cause added strain on the economy. Countries spend a lot of money on the protection of the environment. It was estimated that the US environmental protection plan has spent more than 150 billion dollars environmental protection [14]. A reduction in sources of fossil fuels will add strain to the society. The constant use of fossil fuels will lead to some depletion necessitating innovative alternatives. Therefore, of the use of liquid biofuels could effectively substitute a portion of the fossil transportation fuels.

\section{RENEWABLE ENERGY}

In 2014 renewable energy contributed around $13.8 \%$ to the worldwide energy supply, [15], with around $10.1 \%$ coming from biofuels and waste sources. [8] projected an annual increase of $2.6 \%$ in renewable sources, such as biodiesel. The biggest contributor to renewable sources is biofuels, outranking hydropower [15].

Biofuels are produced from renewable resources and is environmentally friendly due to biological carbon fixation and is proposed to be better sources of sustainable energy [16]. There are currently two types of biofuels. The first is primary biofuels which are produced from unprocessed organic materials, while the secondary biofuels are processed from biomass [17]. There are different types of biofuels made from various renewable resources or chemical reactions [18] are:

- Bioethanol

- Biodiesel

- Bio-methanol

- Bio-butanol

\section{A. Biodiesel}

Biodiesel is an alternative source for diesel. First generation biofuels are produced from oils directly extracted from crops. First generation biofuels increase the deforestation and have a 
negative impact on the biodiversity [19]. Due to this concern, the first generation biofuels is not the best option to produce biodiesel. An example of first-generation biofuels is sunflower and palm oil. Whereas, second-generation biofuels are produced from non-food crop feedstock, for example, organic waste and food crop waste [19]. An example of second-generation feedstock is waste cooking oil which is used to produce second generation biofuels. Oils and alcohols are needed to produce biodiesel. Biodiesel consists of two types of reaction processes, namely transesterification and esterification. There are different stages in the production of biodiesel. The first is to convert the fatty acids into biodiesel by using the transesterification process and afterward, alcohol and a catalyst must be used to get a higher biodiesel conversion. After the fatty acid turns into biodiesel, must the biodiesel settle to form two layers namely: a biodiesel layer and a glycerol layer. The layers need to be separated and then the biodiesel layer must be purified to remove all the impurities, alcohols and catalysts in the mixture [20].

\section{1)Feedstock}

Biodiesel is produced using various feedstocks from renewable resources. Biodiesel biofuel can be produced from waste cooking oil (WCO) and animal fats. A vegetable oils molecule consist of a chemical structure that includes a glycerol molecule and a fatty acid molecule. Triglycerides, as the primary product of the reaction of vegetable oil, are esters, which are formed from glycerol via the process of esterification to form three hydroxyl groups with fatty acid chains [22]. Vegetable oils can be characterized by their physical and chemical properties to produce biodiesel. Table I shows the chemical and physical properties of different oils in relation with its fuel related properties which include kinematic viscosity, cetane number, heating values, cloud point and flash point.

Table I: Chemical And Physical Properties Of Oils In Relation With DIESEL RELATED PROPERTIES ([21], [23], [24])

\begin{tabular}{lllll}
\hline \hline Vegetable oil & $\begin{array}{l}\text { Kinematic } \\
\text { viscosity } \\
40^{\circ} \mathrm{C} \\
(\mathrm{mm} 2 / \mathrm{s})\end{array}$ & $\begin{array}{l}\text { Cetane } \\
\text { number }\end{array}$ & $\begin{array}{l}\text { Flash } \\
\text { Point } \\
\left({ }^{\circ} \mathrm{C}\right)\end{array}$ & $\begin{array}{l}\text { Density } \\
(\mathrm{kg} / \mathrm{l})\end{array}$ \\
\hline Palm & 39.6 & 42.0 & 267 & 0.918 \\
$\begin{array}{l}\text { Sunflower } \\
\begin{array}{l}\text { Diesel } \\
\text { requirements }\end{array}\end{array}$ & 33.9 & 37.1 & 274 & 0.916 \\
\hline \hline
\end{tabular}

Biodiesel can be produced from the above-mentioned oils by using the transesterification process to convert the FFA's into esters.

\section{2) The production of biodiesel}

\section{a) Feedstock pre-treatment}

The impurities produced by free fatty acids (FFA) and water, in oil feedstock, can affect the biodiesel quality and thus is pre-treatment needed. The higher the moisture content of the oil, the higher the likelihood of soap formation taking place during the transesterification process [25]. One method to remove the water in the oil is by heating the oil up to $100^{\circ} \mathrm{C}$ in an oven or over a heating mantle. Thereafter, the oil must be filtered in order to ensure that no food particles or large solid impurities are present in the oil before the esterification and/or transesterification process begins.

\section{b) Esterification}

After the pre-treatment of the oils, the esterification process can be performed where the FFA's are converted into usable oils from which biodiesel can be produced. Various methods can be used in order to convert the FFA's into usable biodiesel and each method has its own limitations. A well-known FFA process is acid esterification. Methanol is mostly used because it cost less than the other alcohols used to produce biodiesel [4]. Alcohol is needed to transform the triglycerides into esters. Esterification is where a free fatty acid converts into an ester by using an acid catalyst with an alcohol where water is the by-product of this reaction [26]. The product yield depends on the extent as to which the esterification process is used to remove FFA's, as the amount of FFA present affects the transesterification process. The lipids consist of FFA's and an acid is needed to remove the FFA from the lipids in order to get esters. A titration method is used in order to see if there is a high amount of FFA present in the oil [22]. The product yield depends on the extent as to which the esterification process is used to remove the FFA's, as the amount of FFA present affects the transesterification process [28].

\section{c) Transesterification}

The second process is known to be transesterification, where an alcohol is mixed with alkali catalyst and the mixture reacts with the fatty acids of the oils. The fatty acid chains break down and form FAME biodiesel. The transesterification is the most important part of producing biodiesel and has around $98 \%$ conversion yield [29].

\section{d) Biodiesel production parameters}

There are various reaction factors that influence the biodiesel production and quality. The flowing parameters can influence the biodiesel production and quality: reaction time, the type of catalyst and alcohol ratios needed with respects to the oil feedstock and the reaction temperature.

\section{(1) Reaction Time}

According to [31], the conversion of the FFA into esters increases with the reaction time but the equilibrium state for the production of biodiesel normally starts around $90 \mathrm{~min}$. A longer reaction time does not increase the yield of the product.

\section{(2) Catalyst}

There are various types of catalyst that can be used for biodiesel production. The catalyst is divided into two groups namely: heterogeneous and homogeneous. These 2 groups are divided into different types of catalysts which include: acid-, alkali, enzymatic and whole cell enzyme catalysts [32]. According to [32] is the homogeneous alkaline catalyst the most effective catalyst for biodiesel production due to the high conversion to product in "mild conditions." Although, the reaction for homogeneous catalyst is fast must the catalyst be neutralized and thus can it not be reused or recovered [33]. Acid-homogeneous catalyst is only used if the FFA is less than $4 \%$. 


\section{(3) Esterification reaction}

For the esterification reaction, an acid catalyst of concentrated sulphuric acid will be used in order to convert the FFA's into esters. According to [34], a study was done where it has been proven that an acid-catalyst of $1 \mathrm{wt}$. $\%$ of the oil results into a better conversion from triglycerides to esters.

\section{(4) Transesterification Reaction}

Sodium hydroxide and potassium hydroxide as a catalyst can be used for the transesterification reaction. According to [35], a $98.0 \mathrm{wt}$. \% yield of the product is obtained when WCO is used as feedstock with $\mathrm{KOH}$ as a catalyst. A 1 wt. \% $\mathrm{KOH}$ amount of catalyst is needed for the amount of oil used.

\section{(5) Alcohol}

An excess amount of alcohol is needed to obtain a maximum conversion. According to [31], a conversion of $99.5 \%$ is achieved when an alcohol to oil ratio of $6: 1$ is used. According to [36] can a molar ratio of 3:1 of methanol to oil be used for transesterification.

\section{(6) Reaction Temperature}

By increasing the reaction temperatures, the viscosity of the oils will be reduced which aids with the mixing of the oils with the alcohol-catalyst mixture but there are limits to where the methanol starts to evaporate and the catalyst to deactivate. Normal reaction temperatures is around $50-60{ }^{\circ} \mathrm{C}$ [29].

\section{(7) Mixing Speed}

The mixing speed of the reagents can cause the yield of the product to decrease. The alcohol and oil mixture are not miscible and if the reaction speed is too slow will the two reagents not mix in order to convert the oils into esters [31].

\section{3)Post-treatment Separation process}

After the production of biodiesel, the settling of glycerol and biodiesel initiates. The two layers separate because of a difference in density and polarity. Glycerol is soluble in water whereas, biodiesel is hydrophobic [42]. After the separation step, the biodiesel can be polished. Wet washing can be used to purify the biodiesel so that the turbidity value of the biodiesel becomes smaller.

\section{4)Quality of biodiesel}

According to the [45], the D7213-12e1 standard test method for the boiling range of petroleum distillates cannot be used for "materials containing heterogeneous components", such as esters. The quality of biodiesel is the utmost important aspect of selling biodiesel to the market. According to [3] and [47], the following characteristics are important when evaluating the quality of B100 (100\% pure biodiesel):

TABLE II: SABS CRITERIA FOR B100 [48]

\begin{tabular}{ll}
\hline \hline Parameter & Range \\
\hline \hline Density at $15^{\circ} \mathrm{C}$ & $860-900 \mathrm{~kg} / \mathrm{m} 3$ \\
\hline Cetane number min & 51.0 \\
Ester content & $96.5 \mathrm{wt} \%$ \\
Contamination & $24 \mathrm{mg} / \mathrm{kg}$
\end{tabular}

\section{B. Simulated distillation method}

Diesel and biodiesel have the same boiling point distribution. The boiling point range of diesel is around 180$360^{\circ} \mathrm{C}$. In this test, method petroleum is used with an initial boiling point of $100^{\circ} \mathrm{C}$ and a final boiling point less than $360^{\circ}$ $\mathrm{C}$ at atmospheric pressure [45]. The Gas Chromatography is used to get a calibration curve for the different components in the boiling ranges of $100-615^{\circ} \mathrm{C}$. Calibration values are needed to simulate the calibration simulation plot in order to see the tendency of different components and their boiling points. The ASTM D7213-12 is a test method which uses a gas chromatography to simulate the boiling range of petroleum distillates [45]. The solvent for the GC must be a polar and must not interfere with the sample used in the GC thus must the solvent have a boiling range smaller than $100^{\circ}$ [45]. The GC must be equipped with a "non-polar open tubular GC column" with helium or nitrogen as carrier gas [45]. The sample must be diluted with a solvent which can be introduced into the GC which vaporizes the sample and separating the various molecules for the sample. The column temperature must be raised in order to separate all hydrocarbons in the mixture. A flame ionization detector is used to detect the hydrocarbon components with their various boiling points which are detected on a computer representing time intervals for different pike areas. The retention times are used to obtain the boiling ranges for the components and is plotted on a cumulative curve. In this study, a mass spectrometry was used in the case of the FID with a large column than specified.

\section{Distillation method}

Distillation is normally used to separate different products from a mixture by changes in the phase conditions [50]. Fractional distillation, mostly used for petroleum products where different volatile products are distilled into a valuable product. According to [50], fractional distillation is used when the boiling points of components are very close and each component is vaporized into the column, where it condenses into the packing material of the column.

The ASTM D86 standard test method is used in order to use the distillation of petroleum products under ambient pressure of $86.02 \mathrm{kPa}$ [51] for both the biodiesel and diesel. The standard was adapted for this study in order to obtain the results. ASTM D86 indicates that the specimen with the sample must be operated in the same conditions as to which the sample conditions are indicated [52]. The distillation can be performed at ambient pressure under conditions that replicates one theoretical plate where the different temperature ranges can be observed. The volumes/mass and temperature readings must be done incrementally. The results must be plotted as percentage evaporated distillate vs the boil off temperature (this is also known as the distillation curve) [52].

\section{OVERVIEW OF THE STUDY}

The main study in this project will be to compare the simulated distillation (ASTM D7213) with the atmospheric distillation (ASTM D86) results for different categories of biodiesel. The objectives for this study is as follows: 
1. Produce biodiesel from various feedstock's, including waste cooking oil, palm oil and sunflower oil. Analyze each feedstock for the fatty acid content in order to determine if the esterification step must be done first to eliminate all carboxylic acids before the transesterification reaction.

2. Analyze the biodiesel product to ensure that the SANS specifications are met.

3. Compile a distillation curve for the various biodiesels using actual distillation.

4. Compile simulated distillation curves for each biodiesel using the GC-MS results.

5. Compare the actual distillation with the simulated distillation results. The actual distillation is done 3 times for each experiment in order to get the average result for this study

\section{V.EXPERIMENTAL METHOD}

The experimental procedure for this study is conducted in this chapter.

Materials

1)Feedstock

A list of feedstocks used are given in Table III.

TABLE III: FEEDSTOCK'S USED FOR EXPERIMENTS

\begin{tabular}{ll}
\hline \hline Component & Purpose \\
\hline Sunflower oil & Feedstock for biodiesel production \\
Palm oil & Feedstock for biodiesel production \\
Waste cooking oil & Feedstock for biodiesel production \\
Biodiesel & Feedstock for distillation \\
\hline \hline
\end{tabular}

\section{B. Biodiesel production from various feedstock's}

The experimental method for the production of this study is discussed in this section. This includes the analyses of the feedstocks and the preparation of the feedstock before it is mixed with the alcohol-catalyst mixture. Thereafter, the experimental method of the biodiesel production will be discussed. [37] - [41] was used to indicate the amount of catalyst and alcohol needed for the production of the biodiesels from the various feedstock's.

\section{1)Characterization of feedstock's}

Each feedstock used for this experiment has been analyzed in order to determine if the production must be a two-step reaction and the amount of water present in the feedstock.

TABLE IV: FFA VALUES FOR FEEDSTOCKS

\begin{tabular}{ll}
\hline \hline Feedstock: & FFA value \\
\hline Sunflower oil & $1 \%$ \\
Palm oil & $3.44 \%$ \\
WCO & $4.57 \%$
\end{tabular}

An FFA value of larger than $4 \%$ is used to produce biodiesel via esterification. Thus to conclude, the WCO biodiesel was produce using the two-step reaction. The water content values for all three feedstocks was high and thus pre-treatment was used in order to reduce the water content of the oil.
TABLE V: WATER CONTENT OF FEEDSTOCK

\begin{tabular}{lll}
\hline \hline Feedstock: & Water content $(\%)$ & Water content $(\mathrm{ppm})$ \\
\hline $\begin{array}{l}\text { Sunflower } \\
\text { oil }\end{array}$ & 0.04 & 408.9 \\
$\begin{array}{l}\text { Palm oil } \\
\text { WCO }\end{array}$ & 0.08 & 804.4
\end{tabular}

\section{Feedstock Preparation}

Each feedstock used to produce the biodiesel for this study is treated before mixing the oils with the alcohol-catalyst mixture.

Each feedstock must firstly be filtered in order to remove all large particles, especially the WCO. A Buchner funnel filter is used under vacuum conditions in order to filter the oil. Each feedstock was then placed in a pot and an oven was used at $100^{\circ} \mathrm{C}$ for 1 hour to evaporate most of the water present in the oil. Occasionally, the oil was stirred and placed back into the oven. Thereafter, the pot is removed from the oven and placed on the counter to cool off.

\section{Biodiesel production}

After the feedstock pretreatment, the production of the biodiesel can commence. Firstly, all reagents must be prepared. The oil feedstock has cooled off and the measuring of both the catalyst and the alcohol is done. For the WCO an acid-catalyst was used due to the high FFA value. Both the sunflower- and palm biodiesel was produce only on transesterification. The esterification reaction method is explained a thereafter, the transesterification method follows.

\section{1)Experimental set-up}

The following apparatus was used in order to produce the biodiesel for this study:

- $2 \mathrm{~L}$ three-neck round bottom-flask

- Thermometer

- Liebig condenser (known as a reflux condenser)

- Heating mantle

- Magnetic stirrer

- Separating funnel

\section{2)Experimental procedure}

\section{I.Esterification}

The main objective of the WCO biodiesel production was to firstly reduce the FFA value by using an acid catalyst and thereafter using an alkali catalyst to convert the oil into biodiesel. The esterification process used $\mathrm{H} 2 \mathrm{SO} 4$ as a catalyst and the catalyst was diluted with methanol in order to mix it with the oil. In order to make the oil less viscous, the oil was firstly heated to $65^{\circ} \mathrm{C}$. A 1 wt. \% catalyst was used and diluted with a $6: 1$ methanol to oil ratio and the mixture was mixed with the WCO inside the $2 \mathrm{~L}$ flask. The catalyst was measured by using a balance. The $2 \mathrm{~L}$ flask, filled with the reagent mixture was placed on a heating mantle and a magnetic stirrer was used to stir the mixture at 400 RPM for 1 hour at a temperature of $65^{\circ} \mathrm{C}$. Table VI shows the amount of catalyst, alcohol and oil used for each reaction. 
TABLE VI: AMOUNT OF USED REAGENTS AND WCO FOR THE ESTERIFICATION REACTION

\begin{tabular}{ll}
\hline \hline Reagent & Amount used \\
\hline Oil & $0.8 \mathrm{~L}$ \\
Methanol & $0.2 \mathrm{~L}$ \\
Catalyst & $7.36 \mathrm{~g}$
\end{tabular}

\section{TRANSESTERIFICATION}

For the sunflower oil and palm oil a one-reaction transesterification process was used whereas for the WCO a two-reaction process was used. The transesterification process converts the FAME into esters by using $\mathrm{KOH}$ as a catalyst. The catalyst was diluted using methanol. The oil was again heated up to $65^{\circ} \mathrm{C}$ and the catalyst-methanol mixture was mixed with the heated oil. More methanol and $\mathrm{KOH}$ was needed for the WCO in order to neutralize the acid catalyst from the esterification reaction. The transesterification for all 3 feedstocks was set at $60^{\circ} \mathrm{C}$ for $90 \mathrm{~min}$. A magnetic stirrer was used to mix the components and the speed was set to 750 RMP. Table VI shows the amount of catalyst, alcohol and oil used for each reaction.

TABLE VII: AMOUNT OF USED REAGENTS AND FEEDSTOCK FOR THE TRANSESTERIFICATION REACTION

\begin{tabular}{lll}
\hline \hline Feedstock & Reagent & Amount used \\
\hline $\begin{array}{l}\text { Sunflower } \\
\text { oil }\end{array}$ & Oil & $1.34 \mathrm{~L}$ \\
& & \\
& Methanol & $0.2 \mathrm{~L}$ \\
& Catalyst & $14 \mathrm{~g}$
\end{tabular}

\section{BIODIESEL POST-TREATMENT}

To produce biodiesel, the unreacted oil was converted into biodiesel and glycerol. Due to the difference in polarities the biodiesel layer and the glycerol layer was separated and the glycerol layer was removed. A separating funnel was used to remove the glycerol from the crude biodiesel. Distilled water was then heated to $70^{\circ} \mathrm{C}$ and then used to wash the crude biodiesel. The washing process was done 3 times (it can be done more than three times unit the water that is separated is clear enough) and the water-biodiesel mixture was mixed in order to separate most of the impurities from the crude biodiesel. The washing process was done every 3 hours in order to give enough time for efficient separation between the two components. After the water wash, the drying of the biodiesel can commence. A flask, filled with biodiesel was placed on the heating plate at $102^{\circ} \mathrm{C}$ while stirring the biodiesel rapidly for 2-3 hours. Afterwards, sample preparation was done for the biodiesel analyses.

\section{Analyses of the biodiesel}

The analysis was done on each biodiesel produced. ISO 3104 test method was used to indicate the dynamic viscosity where the kinematic viscosity is calculated. ISO 2719 was used to determine the flash point of the biodiesel. In order to indicate the acid value of the biodiesel was the SANS 54104 test method used. The Karl Fisher method (ISO 12937) was used to determine the water content in the samples [48].

\section{A. Distillation}

\section{1)Experimental setup}

The following apparatus was used in order to complete this experiment:

- $50 \mathrm{~mL}$ double-neck heart-bottom flask

- Liebig condenser

- 3x $30 \mathrm{~mL}$ mL bottles

- $2 x$ thermocouples with a temperature indicator

- Heating mantle

- Scale

A $50 \mathrm{~mL}$ heart-bottom flask was used and covered by a heating mantle. To prevent external cooling on the distillation unit was insolation used. The $50 \mathrm{~mL}$ flask was filled up with liquid and boiling stones was inserted into the heating mantle. A Liebig cooler was connected to the flask and two thermocouples were connected to the setup. The one thermocouple was connected to the flask and the other at the top of the Liebig cooler. Both thermocouples were connected to a detector in which the temperature was transmitted to the control unit in order to see the temperature for the unit. Measurements of both the top and bottom temperatures were measure at different time intervals.

\section{2)Experimental procedure}

Firstly each empty $30 \mathrm{~mL}$ bottle was weighed. The $2 \mathrm{~L}$ flask was filled with biodiesel until $3 / 4$ of the flask was full. A few boiling stones were used in order to prevent the liquid from boiling over. The flask was placed in the heating mantle and the reflux condenser with the packing was connected to the flask. Both thermocouples where connected to their respective positions and the first $30 \mathrm{~mL}$ bottle were connected to the vapor outlet tube. External cooling such as water was firstly used to condense the liquid in the reflux tube but due to a large internal reflux and external reflux the water source was switched off. Thus, due to high condenser duty too little distillate was formed. Insolation was used in order to prevent external reflux in the column. The heating mantle was switched on by turning the temperature knob above the light blue zone. Both the time and temperatures were measured. After the temperature of the bottom liquid was at $100^{\circ} \mathrm{C}$, the mantle was set to a higher setting in order to increase the temperature. Do not put the mantle to its maximum heat setting because cracking of the diesel will occur. When the bottom temperature of the liquid was around $250^{\circ} \mathrm{C}$ the liquid was starting to boil and the top temperature was increasing. If the temperature at the top of the distillation unit reached 250 ${ }^{\circ} \mathrm{C}$, the mass readings was done for different temperature measurements. If the $30 \mathrm{~mL}$ bottle was full before the set temperature was reached, the bottle was replaced and a temperature and mass measurement was done. When the liquid level in the flask was low, the mantle was switched off and the final measurement of the top and bottom temperatures were done. The final mass measurement was normally done after 30 min since the mantle was switched off because some overhead vapors in the column were still present. 


\section{B. Analyses of the distillation}

1) $G C-M S$

Agilent Technologies 7890 A (GC-MS) was used in order to obtain the simulated distillation results for each component. A VF-5ht column was used with a length of $30 \mathrm{~m}$, diameter of $0.25 \mathrm{~mm}$ and a film thickness of $0.1 \mu \mathrm{m}$. A 10:1 split ratio was used with an injection volume of $1 \mu \mathrm{L}$. The GC-MS was also used to determine the composition of each molecule present in the sample.

Apparatus:

- GC-MS

- Sample bottle

- Balance

Reagents and materials of GC-MS:

- Carrier Gas: Helium

- Dilution: dichloromethane

Firstly, the samples was filtered before measuring the amount needed for the GC-MS. Around $0.02 \mathrm{~g}$ of the filtered sample was needed with $1 \mathrm{~mL}$ of dichloromethane to dilute the sample. The sample was injected into the system and the column oven temperature increased at a linear rate in order to vaporize the sample and separate the molecules effectively. Retention time and pike areas was displayed on the computer in which the retention times for known components was compared to their boiling range. The retention times of known hydrocarbons were used in order to plot the simulated distillation plot for biodiesel. Table VIII shows the standard retention times used to plot the biodiesels simulated distillation plot.

TABLE VIII: KNOWN HYDROCARBON RETENTION TIMES USED

\begin{tabular}{llll}
\hline $\begin{array}{l}\text { Component } \\
\text { Name }\end{array}$ & $\begin{array}{l}\text { Component } \\
\text { Number }\end{array}$ & $\begin{array}{l}\text { Retention } \\
\text { Time }(\mathrm{min})\end{array}$ & $\begin{array}{l}\text { Boiling Point } \\
\left({ }^{\circ} \mathrm{C}\right) \text { at } 86.02 \\
\mathrm{kPa}\end{array}$ \\
\hline Nonane & $\mathrm{C} 9$ & 5.310 & 145 \\
Decane & $\mathrm{C} 10$ & 8.493 & 168 \\
Undecane & $\mathrm{C} 11$ & 11.664 & 188 \\
Dodecane & $\mathrm{C} 12$ & 14.618 & 208 \\
Tridecane & $\mathrm{C} 13$ & 17.020 & 228 \\
Tetradecane & $\mathrm{C} 14$ & 19.599 & 246 \\
Pentadecane & $\mathrm{C} 15$ & 22.159 & 262 \\
Hexadecane & $\mathrm{C} 16$ & 24.351 & 278 \\
Heptadecane & $\mathrm{C} 17$ & 26.637 & 294 \\
Octadecane & $\mathrm{C} 18$ & 28.586 & 307 \\
Nonadecane & $\mathrm{C} 19$ & 30.531 & 320 \\
Eicosane & $\mathrm{C} 20$ & 32.380 & 333 \\
Heinecosane & $\mathrm{C} 21$ & 34.184 & 345 \\
Octadecanoic & ODA & 36.065 & 361 \\
acid & & &
\end{tabular}

\section{RESULTS \& DISCUSSION}

\section{A. Biodiesel production from various feedstock's}

In this section, the quality (according to [48]) of the biodiesel produced is discussed.
1)Analysis of the various biodiesels

TABLE IX: BIODIESEL ANALYSIS

\begin{tabular}{llllll}
\multicolumn{6}{c}{ TABLE 1X: BIODIESEL ANALYSIS } \\
\hline \hline Biodiesel & $\begin{array}{l}\text { Viscosity } \\
\left(\mathrm{mm}^{2} / \mathrm{s}\right)\end{array}$ & $\begin{array}{l}\text { Flash } \\
\text { Point } \\
\left({ }^{\circ} \mathrm{C}\right)\end{array}$ & $\begin{array}{l}\text { Acid } \# \\
(\mathrm{mg} \\
\mathrm{KOH} / \\
\mathrm{g})\end{array}$ & $\begin{array}{l}\text { Density } \\
\left(\mathrm{kg} / \mathrm{m}^{3}\right)\end{array}$ & $\begin{array}{l}\text { Water } \\
\text { content } \\
(\mathrm{ppm})\end{array}$ \\
\hline $\begin{array}{l}\text { Sunflower } \\
\text { biodiesel }\end{array}$ & 4.077 & 145.0 & 0.11 & 883 & 0.03 \\
$\begin{array}{l}\text { Palm } \\
\text { biodiesel }\end{array}$ & 4.432 & 145.0 & 0.24 & 880 & 220.8 \\
$\begin{array}{l}\text { WC } \\
\text { biodiesel }\end{array}$ & 3.950 & 155.0 & 0.49 & 886 & 796.5 \\
Biodiesel & 4.432 & 203.7 & 0.58 & 896 & 143.7
\end{tabular}

The WCO biodiesel had a high water content amount which was rectified by placing the biodiesel inside an oven at $100^{\circ} \mathrm{C}$ for 3 hours in order to remove the excess water in the product. All the other requirements mentioned in this section meets the SANS 1935:2011 standards and the quality of the biodiesel is within the ranges of the SANS 1935:2011.

\section{B. Distillation}

The distillation resulted in much better results with only an average volume of $<5.47 \mathrm{wt}$. \% left as residue, which means coke formation still occurred, but at a much lower rate. In Fig 4 the simulated distillation results are shown alongside the experimental distillation results.

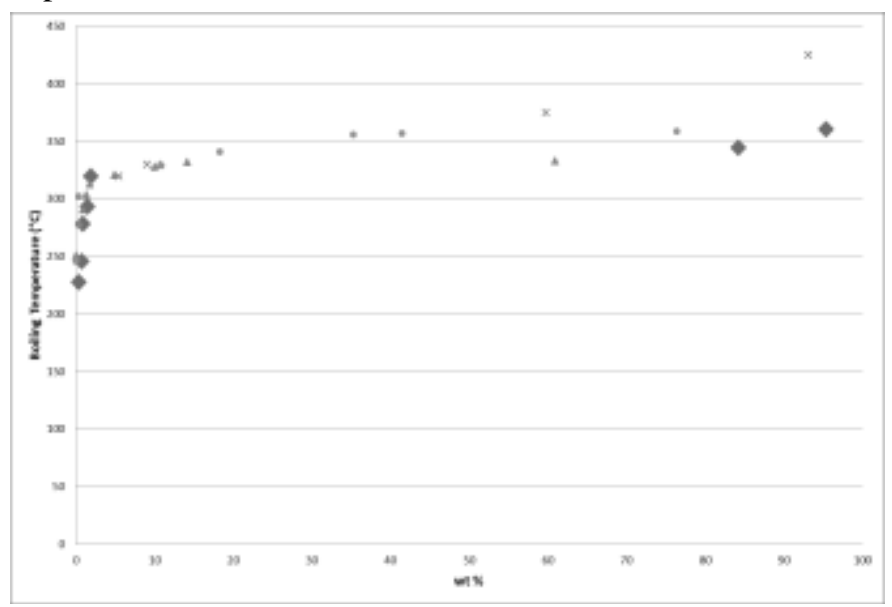

Fig. 4: Experimental distillation plot in terms of simulated distillation plot for biodiesel (× Run $1 \boldsymbol{\Delta}$ Run $2 \bullet$ Run $3 \bullet$ Simulated results)

Fig 4 shows that the experimental runs have tended to have the same tendency as the simulated distillation results. An average experimental error of $1.85 \%$ was obtained for the distillation experiment for the biodiesel. Run 1 has a large end boiling range as the simulated distillation results and this occurred due to cracking in the molecules whereas, run 2 has a lower boiling temperature at $62 \%$ than for run 1 . An average of $<1 \%$ was predicted for the simulated distillation results with respects to the experimental results. All these results show that cracking of the molecules have occurred but the amount of coking left was a smaller fraction as in the large fractional distillation unit. The experimental distillation results are shown in Fig 5 for the sunflower biodiesel produced. 


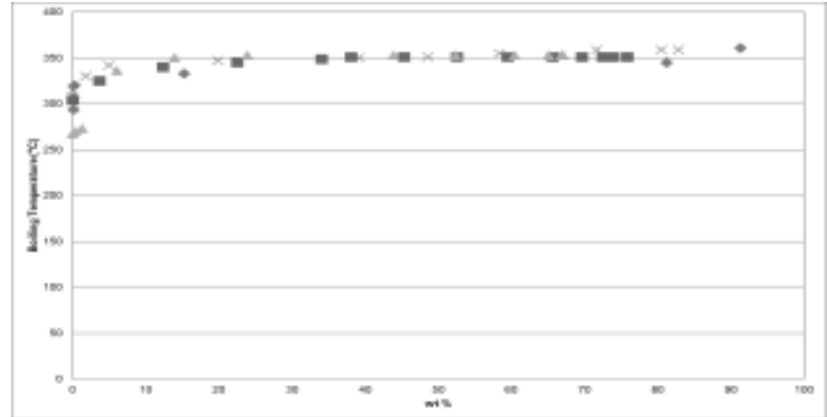

Fig. 5: Experimental distillation plot in terms of simulated distillation plot for sunflower biodiesel (× Run $1 \boldsymbol{\Delta}$ Run 2 a Run $3 \bullet$ Simulated results)

Fig 5 shows that the boiling range for run two started at a lower temperature than the simulated data. An average experimental error of $2.21 \%$ was obtained for this experiment. At $345^{\circ} \mathrm{C}$, all the experimental results are located in the same range as the simulated result. The last data point for the simulated results is located at $372^{\circ} \mathrm{C}$. Due to coke formation, 3 experiments had not reached the boiling range of $372^{\circ} \mathrm{C}$. Water formed during the distillation for the first run. The possibility for water formation during the distillation experiment is due to cracking of the molecules. As explained before does cracking cause that molecules tend to become shorter-chain molecules. Esters consist of hydrogen, carbon and oxygen molecules and cracking causes that the hydrogen bonds between the molecules becomes weaker. This has been proven by using copper sulfate and testing the components present in the sample taken from the overhead distillates. This shows that the cracking of molecules occurred in the biodiesel and that the hydrogen bond between the molecules has become weaker and water molecules formed during the distillation process. The water test indicated that the lower layer is thus water present in the sample. The top layer was tested with the GC-MS in order to indicate the molecules present in the sample. A large amount of furan was indicated in the sample. The GC-MS results showed that there is still esters present in the sample and thus is the separation between the water and ester layer observed. An average of $3.56 \%$ error was calculated for the average distillation results in terms of the simulated distillation results. Thus is the experimental results around $3.56 \%$ out of range from the simulated distillation results.

Figure 6 shows the boiling temperatures for the palm oil biodiesel. An average experimental error was calculated as $2.78 \%$ for the distillation of the palm biodiesel.

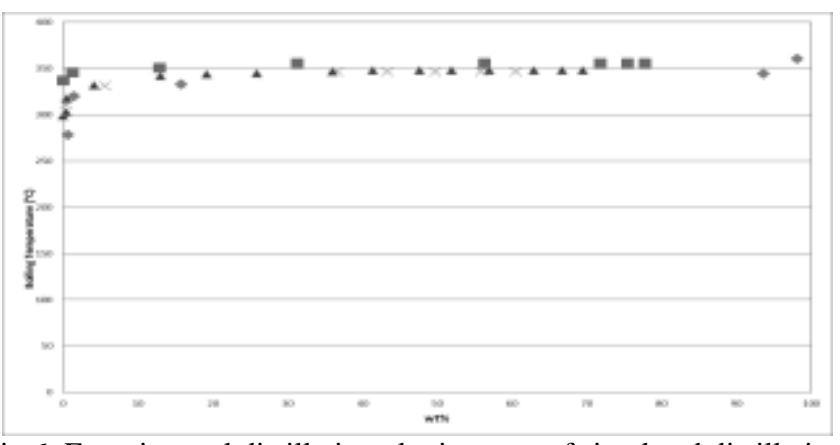

Fig 6: Experimental distillation plot in terms of simulated distillation plot for palm biodiesel ( $\times$ Run $1 \boldsymbol{\Delta}$ Run 2 - Run $3 \bullet$ Simulated results)
Fig 6 indicates that a higher boiling range for run 1 was obtained than for the other two runs. Run 1 started at a boiling range of $346^{\circ} \mathrm{C}$. This high boiling range shows that cracking has occurred in the earlier stages of the distillation experiment. Run 2 and 3 tend to have the same tendency but run 3 has lost a lot of weight due to the formation of coke. Run 3 has formed $9.39 \mathrm{~g}$ of coke after the distillation experiment. Coke formation was caused by the cracking of the biodiesel molecules. A higher boiling point for the C16:0 was obtained and due to its higher boiling point was cracking for the last molecules observed. Due to coking, more than 20 wt. \% of all three runs is lost and could the last two components not be reached at their respective boiling ranges. Run 1 has distilled 9,12-Octadecadienoic acid at a boiling range of $356^{\circ} \mathrm{C}$ with a $77 \mathrm{wt} \%$ whereas for the simulated results thus the same component boils off at $357^{\circ} \mathrm{C}$ at 93.61 wt.\%. It is also possible that both 9, 12- Octadecadienoic acid and 9-Octadecadienoic acid could have been boiled off at $356^{\circ} \mathrm{C}$ for run 1 . Run 2 and run 3 has a smaller weight percentage due to a large residue fraction left in the flask. All the three experiments showed that it has the same distillation curve as the simulated results. The experimental results is an average of $6.31 \%$ out of range from the simulated distillation results. More than $30 \mathrm{wt}$. \% was lost during the experiments due to coke formation. Coke formation has caused that a higher error for the experimental results in terms of the simulated results.

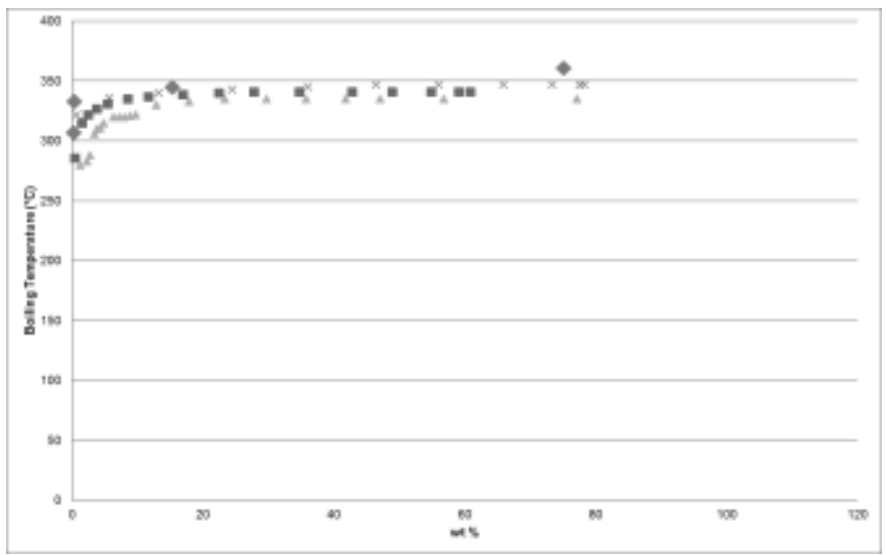

Fig. 7: Experimental distillation plot in terms of simulated distillation plot for WC biodiesel ( $\times$ Run $1 \boldsymbol{\Delta}$ Run 2 — Run 3. Simulated results)

Figure 7 shows the results obtained for the WCO biodiesel distillation. An average experimental error for the WCO distillation was calculated as $2.91 \%$. The first run for this experiment showed that the last distilled component was reached at $340^{\circ}$ with 60.8 wt. \% due coke formation. Both the second and the third run ended at a boiling temperature of $335^{\circ}$ and $347^{\circ} \mathrm{C}$. Fig 7 represent that for $\mathrm{WCO}$ the experimental results tend to be lower than for the simulated results. The WCO biodiesel experiments tend to be lower than the simulated distillation plot. This leads to lower boiling ranges for the WCO biodiesel. Run 2 and 3 has a larger end weight with less coke formation formed at the end of the experiment. Although the column was insolated could the insolation not have been $100 \%$ efficient due to external reflux 
preventing the molecules to become vapors and have led to cracking of the molecules leading to a large amount of coke formation. Fig 4-7 shows the predicted error for the simulated distillation results with respects to the average experimental results obtained. The error between the average experimental results is around $3.79 \%$ out of range from the simulated distillation results.

Fig 8 represents all the actual distillation experiments done. As can see in Figure 8 do all experiments follow the same tendency except for the WCO BD run 2 and the palm BD run 3 . This is led by cracking in the biodiesel molecules which tend to change the boiling temperature for the experiment. The palm BD run 3 has started at a lower boiling temperature as the rest of the experiment whereas the WCO run 2 has had a large end temperature but also has the largest amount of weight present in the distillate.

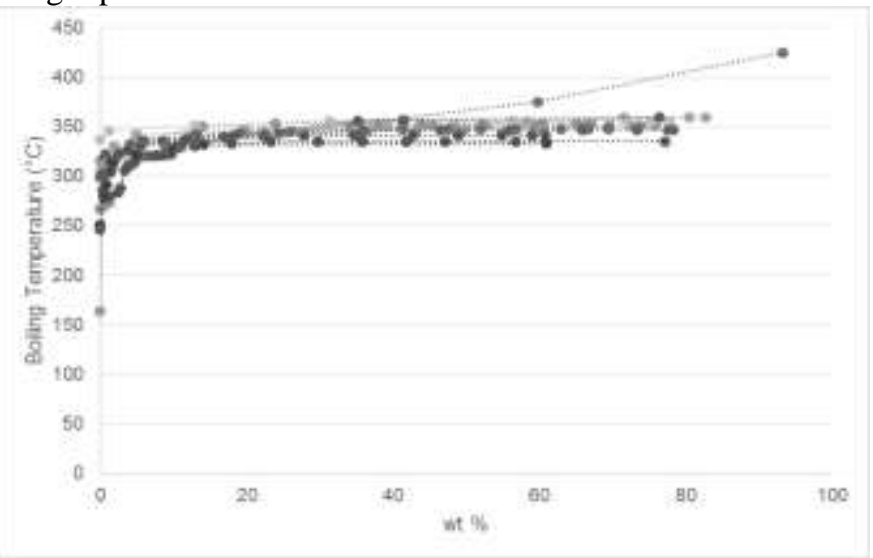

Fig. 8: All biodiesel distillation experiments

Fig 8 represents all the distillation experiments obtained. Figure 8 shows that all biodiesels used have the same distillation plot. Thus can biodiesel be used to compare the simulated distillation results with the actual distillation results. To conclude this section, all graphs for the small distillation unit tend to have the same curve as for the simulated distillation. Thus can heterogeneous components, such as esters be used to compare the simulated distillation results with the actual distillation results but due to cracking in the molecules can some biodiesels tend to have a lower or higher boiling temperature due their oxidation stability for each feedstock.

\section{CONCLUSIONS}

The possibility to determine the distillation curve of biodiesel using ASTM D72 method was studied. The production of biodiesel from various feedstocks was successfully done. The scope of this study did not entail that the biodiesel production must be optimized and thus was different studies used to produce the biodiesel. The palm- and sunflower biodiesel were produced from a one-reaction step whereas, for the WCO biodiesel a two-step reaction was used. The two-step reaction for biodiesel includes both esterification and transesterification whereas the one set only includes the transesterification process. Important parameters where measure during the production of the biodiesel. An average reaction temperature of $64^{\circ} \mathrm{C}$ was used with a methanol to oil ratio of 6:1. A 1 wt. \% catalyst was used for both the acid- and alkali reaction. A 2 wt. \% of $\mathrm{KOH}$ was used for the palm oil due to a large FFA value obtained. An average of $60 \mathrm{~min}$ was used for each reaction and an induction test was done in order to indicate if any unreacted oil is still present in the reaction during the reaction time. This indication test uses $9 \mathrm{~mL}$ of methanol with $1 \mathrm{~mL}$ of the biodiesel sample. This test is only used during the production of the biodiesel. Viscosity, water content, and the flash point helped to indicate if the biodiesel produced is according to SANS standard. Each parameter used to test the quality of the biodiesel has met the quality standards and thus can the distillation experiments commence.

ATSM indicates that heterogeneous components such an ester cannot be used for the simulated distillation plot. Various retention times of known hydrocarbons are used in order to get the boiling range for biodiesel. A simulated distillation plot for the biodiesel is plotted and compared to the actual distillation results. The distillation unit location was also changed due to vapors forming during the experiment.

A small experimental error was calculated for the distillation experiments. Each distillation experiment has been done 3 times in order to optimize the results obtained.

The end result has shown that the actual distillation for biodiesel can be compared to the simulated distillation because all the experiments done for this experiment have shown to obtain the same tenancy as for the simulated distillation. There is an experimental error obtained for each experiment due to factors that could not have been controlled during the experiments such as environmental temperatures causing that a higher amount of energy is needed to boil the biodiesel. Cracking is caused by the formation of short-chain molecules and lower boiling temperatures was indicated for these molecules. All the biodiesel experiments began at lower boiling pressures as indicated by the simulated distillation curve due to cracking. Although coke formation had occur during each experiment was is a small enough percentage to prove that simulated distillation can be compared by actual distillation for biodiesel produced from various feedstocks.

\section{X.REFERENCES}

[1] SABS, "SANS 54104:2007," SABS, Pretoria, 2007.

[2] R. Kotrba, "A Proven Biodiesel Process Technology Track record," Biodiesel Magazine, p. 38, 09 January 2017.

[3] US Department of Energy, "Alternative Fuels Data Center," September 2016. [Online]. Available: http://www.eia.gov/biofuels/biodiesel/production/. [Accessed 27 February 2017].

[4] S. Romano and P. Sorichetti, Dielectric Spectroscopy in Biodiesel Production and Characterization, Springer, 2011.

[5] G. Knothe, "Historical perspectives on vegetable oil-based diesel fuels," 2001, pp. 1103-1107.

[6] ASTM International-Standards Worldwide, "Home," s.a.. [Online]. Available: https://www.astm.org/. [Accessed 7 March 2017].

[7] M. Kumar and M. P. Sharma, "Selection of potential oils for biodiesel production.," Renewable and Sustainable Energy Reviews, vol. 56, no. April, pp. 1129-1138, 2016.

[8] U.S. Energy Information Administration, "EIA projects 48\% increase in world energy consumption by 2040," 2016. [Online]. Available: https://www.eia.gov/todayinenergy/detail.php?id=26212. [Accessed 10 July 2017]. 
[9] Energy.Gov, "Fossil," s.a.. [Online]. Available: http://energy.gov/science-innovation/energy-sources/fossil. [Accessed 2017 May 23].

[10] IER, "Fossil Feuls," 2016. [Online]. Available: http://instituteforenergyresearch.org/topics/encyclopedia/fossil-fuels/. [Accessed 13 July 2017].

[11] IEA, “Coal," [Online]. Available: http://www.iea.org/topics/coal/. [Accessed 13 July 2017].

[12] Ecotrucuty, "The end of fossil fuels," 2011. [Online]. Available: https://www.ecotricity.co.uk/our-green-energy/energyindependence/the-end-of-fossil-fuels. [Accessed 13 July 2017].

[13] D. M. Canes, "Fossil Feul Energy and Economic Wellbeing," The George C. Marshall Institute, 2015.

[14] W. A. Pizer, R. D. Morgenstem and J. S. Shih, "The Cost of Environmental Protection," Resources for the Future, vol. 1, no. Nov, pp. 732-738, 2001.

[15] IEA, "Key Renewables Trends," International Energy Agency, 2016.

[16] H. Lee, W. C. Clark and C. Devereaux, "Biofeuls and Sustainable Development," Land \& Sea Venice International University, Italy, 2008.

[17] GreenFact, "Liquid Biofuels for Transport Prospects, risks and opportunities," $\quad$ s.a.. $\quad$ [Online]. Available: https://www.greenfacts.org/en/biofuels/l-2/1-definition.htm. [Accessed 13 July 2017’]

[18] Biofuel.org.UK, "Biofuels: What are they?," s.a.. [Online]. Available: http://biofuel.org.uk/. [Accessed 2017 May 23].

[19] R. Sims, M. Taylor, J. Saddler and W. Mabee, "From 1st- to 2ndgeneration biofuels technologies: An overview of current industry and RD\&D activities," IEA Bioenergy, Paris, 2008.

[20] S. D. Romano and P. A. Sorichetti, "Chapter 2: Introduction to Biodiesel Production," in Dielectric Spectroscopy in Biodiesel Production and Characterization, London, Springer-Verlag, 2011, p. 16.

[21] S. Singh and D. Singh, "Renewable and Sustainable Energy Reviews," Indore, 2009.

[22] Dictonary.com, "Triglyceride," 2007.

[23] P. Giannelos, S. Sxizas, E. Lois, F. Zannikos and G. Annastopoulos, "Physical, chemical and fuel related properties of tomato seed oil for evaluating its direct use in diesel engines," National Technical University of Athens, Greece, 2004.

[24] L. Barker, "Specification for Fuel Oils for Coal Fired Boilers Standards," Eskom, 2017

[25] S. International, "High FFA Pretreatment," 2013. [Online]. Available: http://www.srsbiodiesel.com/technologies/esterification/high-ffapretreatment/. [Accessed 18 July 2017].

[26] K. Addison, The Biodiesel Bible, Journey to Forever, n.d.

[27] J. Ashenhurst, "Conversion of carboxylic acids to esters using acid and alcohols (Fischer Esterification)," s.a. [Online]. Available: http://www.masterorganicchemistry.com/reaction-guide/conversionof-carboxylic-acids-to-esters-using-acid-and-alcohols-fischeresterification/. [Accessed 25 May 2017].

[28] Metrohm, "Acid value, free fatty acids," Metrohm, s.a..

[29] ESRU, "What is biodiesel?," s.a.. [Online]. Available: http://www.esru.strath.ac.uk/EandE/Web_sites/0203/biofuels/what_biodiesel.htm. [Accessed 23 May 2017].

[30] S. Lele, "Trans-Esterification BioDiesel Process," s.a.. [Online]. Available: http://www.svlele.com/biodiesel_process.htm. [Accessed 23 May 2017].

[31] A. Gashaw, T. Getachew and A. Teshita, "A Review on Biodiesel Production as Alternative Fuel," Journal of Forest Products \& Industries, vol. 4, no. 2, pp. 80-85, 2015

[32] P. Ravindra and K. R. Jegannathan, "Production of biodiesel using lipase encapsulated in k-carrageenan," SpringerBriefs in Bioengineering, pp. 28-34, 2015.

[33] M. Hajjari, M. Tabatabaei, M. Aghbashlo and H. Ghabavati, "A review on the prospects of sustainable biodiesel production: A global scenario with an emphasis on waste-oil biodiesel utilization," Renewable and Sustainable Energy Reviews, vol. 72, pp. 445-464, 2017.

[34] O. Farobie and Y. Matsumura, "State of the art of biodiesel production under supercritical conditions," Progress in Energy and Combustion Science, vol. 63, no. November, pp. 173-203, 2017.

[35] A. B. Fadhil, E. B. Al-Tikrity and M. A. Albadree, "Biodiesel production from mixed non-edible oils, castor seed oil and waste fish oil," Fuel, vol. 210, no. December, pp. 721-728, 2017.
[36] A. P. Vyas, J. L. Verma and N. Subragmanyam, "Effects of Molar Ratio, Alkali Catalyst Concentration and Temperature on Transesterification of Jatropha Oil with Methanol under Ultrasonic Irradiation," Advance in Chemical Engineering and Science, vol. 1, pp. 45-50, 2011.

[37] P. Verma and M. P. Sharma, "Review of process parameters for biodiesel production from different feedstocks," Renewable and Sustainable Energy Reviews, vol. 62, pp. 1063-1071, 2016.

[38] L. T. Thanh, K. Okitsu, L. Van Boi and Y. Maeda, "Catalytic Technologies for Biodiesel Fuel Production ad Utilization of Glycerol: A Review," Catalysts, vol. 2, pp. 191-222, 2012.

[39] A. A. Refaat, N. K. Attia, H. A. Sibak, S. T. El Sheltawy and G. I. ElDiwani, "Production optimization and quality assessment of biodiesel for waste vegetable oil," International Journal of Environmental Science and Technology, vol. 5, no. 1, pp. 75-82, 2008.

[40] N. C. Nodede, "Continuous microwave-assisted biodiesel production," North-West University, Nort-West, 2016.

[41] R. J. Venter, "Process grease: A possible feedstock for biodiesel production," NWU, Potchefstroom, 2013.

[42] W. M. Center, "Small Scale Biodiesel," s.a.. [Online]. Available: http://www.istc.illinois.edu/tech/small-scale-biodiesel.pdf. [Accessed 23 May 2017].

[43] M. Berrios and R. L. Skelton, "Comparison of purification methods for biodiesel," Chemical Engineering Journal, vol. 144, no. 3, pp. 459465, 2008.

[44] R. Da Tech, "Acid Number to FFA Conversions," s.a.. [Online]. Available: http://www.make-biodiesel.org/Biodiesel-Chemsitry/acidnumber-to-ffa-conversions.html. [Accessed 23 May 2017].

[45] ASTM International, "Standard Test Method for Boiling Range Distribution of Petroleum Distillates in the Boiling Range from 100 to $615^{\circ} \mathrm{C}$ by Gas Chromatography," ASTM, United States, 2012.

[46] A. Al-Otoom, M. Allawzi, A. Ajlouni, F. Abu-Alrub and M. Kandah, "The use of oil shale ash in the production of biodiesel from waste vegetable oil," Journal of renewable and sustainable energy, vol. 4, no. 6, 2012.

[47] A. ASTM International, "Standard Test Method for Cloud Point of Petroleum Products and Liquid Fuels," 2016. [Online]. Available: https://www.astm.org/Standards/D2500.htm. [Accessed 24 May 2017]

[48] SABS, "South African National Standard: Automotive biodiesel Fatty Acid Methyl Esters (FAME) for diesel engines - Requirements and test methods (SANS 1935:2011)". Pretoria Patent ISBN 978-0626-34668-3, 2011.

[49] SABS, "Biodiesel production - Quality management," SABS Standards Division, Groenkloof, 2012

[50] A. M. Helmenstine, "What is Distillation?" 2017. [Online]. Available: https://www.thoughtco.com/what-is-distillation-601964. [Accessed 24 May 2017].

[51] Yr, "Detailed hourly forecast for Potchefstroom, North-West (South Africa)," 2017. [Online]. https://www.yr.no/place/South_Africa/North-

West/Potchefstroom/hour_by_hour_detailed.html. [Accessed 23 Oct 2017].

[52] ASTM International, "Standard Test Method for Distillation of petroleum Products at Atmospheric Pressure," ASTM, United States, 2007.

[53] Anon, "Distillation," 2016. [Online]. Available: http://www.umsl.edu/ orglab/documents/distillation/dist.htm. [Accessed 17 Oct 2017].

[54] SABS, "SANS 54104:2007," SABS, Pretoria, 2007.

[55] Y. M. Shashidara and S. R. Jayaram, "Vegetable oils as a potential cutting fluid- and evolution," Tribology International, vol. 43, pp. 1073-1081, 2010.

[56] J. Clark, "Cracking alkanes," August 2015. [Online]. Available: http://www.chemguide.co.uk/organicprops/alkanes/cracking.html. [Accessed 30 Oct 2017].

[57] Business Dictionary, "Cetane number," s.a..

[58] D. Armstrong, "Laboratory Equipment," s.a.. [Online]. Available: https://www.perkinelmer.com/pdfs/downloads/ATL_EnsuringHighQu alityBiodiesel.pdf. [Accessed 1 March 2017].

[59] U. D. o. Energy, "U.S. Energy Information Administration," 2017. [Online].

Available: http://www.eia.gov/biofuels/biodiesel/production/biodiesel.pdf. [Accessed 7 March 2017]. 
[60] S. Somandepalli, S. Kelly and S. Davis, "Hot Surface Ignition of Ethanol-blended Fuels and Biodiesel". Patent 2008-01-0402, 2008.

[61] Shuan and The Trouts, "BIODIESEL \& SVO DISCUSSION FORUMS," $2005 . \quad$ [Online]. Available: http://biodiesel.infopop.cc/eve/forums/a/tpc/f/629605551/m/84610515 9. [Accessed 23 May 2017].

[62] A. Karmakar, S. Karmakar and S. Mukherjee, "Properties of various plants and animals feedstocks for biodiesel production," Bioresource Technology, vol. 101, no. 19, pp. 7201-7210, 2010.

[63] A. R. Mohammed and R. Bhargavi, "Biodiesel production from waste cooking oil," Journal of Chemical and Pharmaceutical Research, vol. 7, no. 12, pp. 670-681, 2015.

[64] UTAH Biodiesel Supply, "ASTM Tests Explained," s.a.. [Online]. Available: http://www.utahbiodieselsupply.com/astmtests.php. [Accessed 23 May 2017].

[65] M. Limited, "DISTILLATION OF PETROLEUM PRODUCTS," s.a.. [Online]. Available: http://www.mastrad.com/distil.htm. [Accessed 24 May 2017].

[66] Place Analytical, "Identifying Hydrocarbons," s.a.. [Online]. Available: https://www.pacelabs.com/environmental-services/energyservices-forensics/forensics-101-a-primer/identifyinghydrocarbons/page-4.html. [Accessed 19 July 2017].

[67] A. N. Phan and T. M. Phan, "Biodiesel production from waste cooking oils," Fuel, vol. 87, pp. 3490-3496, 2008.

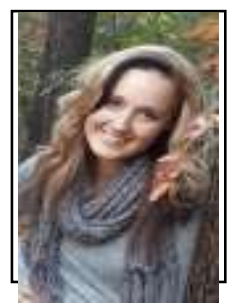

AA van der Merwe a chemical engineering student at NWU. I was born on 12 September $1994 \mathrm{n}$ Vereeniging and is living in Potchefstoom. I am currently a final year student at the NWU Potchefstroom and went to a high school in Vandebijlpark call Driehoek

\section{ACKNOWLEDGMENT}

Firstly, I want to thank God for giving me the ability and resources to complete this study. I would then like to acknowledge and express my gratitude to the following people for their support in assisting me to complete this study:

- My supervisor Corneels Schabort for his support, guidance and advice to complete this study.

- Dr. Roelf Venter for your guidance and support on the biodiesel analysis

- Gideon van Rensburg and Nico Lemmer for your assistance in the laboratory.

- Jan van Zyl en Adrian Brock for helping me with the equipment used to complete this study

- All the staff working at the North-West University for their assistance

- Madelein Pretorius, Delia Chilabade and Nontembiso Piyo for your assistance in working in the laboratory

- JC Stander and Malinda Pieterse for their moral support 